\title{
Polímeros condutores
}

Desde há muito que nos habituámos a associar a condutibilidade eléctrica aos metais bem como o comportamento isolante aos polimeros. No entanto, esta última associação é cada vez menos universal dada a descoberta de materiais poliméricos exibindo surpreendentes propriedades condutoras.

Tudo aconteceu, como tantas vezes em descobertas científicas por um simples "acidente". De facto, em 1977 um estudante de Shirakawa ao repetir uma síntese de poliacetileno num trabalho rotineiro enganou-se. Como consequência obteve um filme flexível com brilho metálico em vez da forma pulverizada habitual. Foi este brilho que despertou a curiosidade de Hegger e Mac Diarmid da Universidade de Filadélfia e os levou a lançar um trabalho de investigação sobre poliacetileno que veio a provocar um enorme interesse em laboratórios de todo o mundo, universitários e industriais. Um polímero com reduzido interesse tornou-se, deste modo, num dos produtos mais estudados nos últimos anos (senão o mais estudado). Explica-se deste modo que ao falarmos sobre polímeros condutores acabemos por dar uma maior ênfase a este material deixando para o final uma referência a outros que revelam igualmente interessantes propriedades eléctricas.

\section{1 - Estrutura do poliacetileno}

O poliacetileno é um polímero de cadeia linear com alternância de ligaçð̃es simples e duplas podendo apresentar-se sob a forma cis e trans. A primeira é a que se obtém quando a polimerização se realiza a baixa temperatura $(195 \mathrm{~K})$ enquanto que a segunda é produzida a temperaturas mais elevadas (433 K). À temperatura ambiente o poliacetileno é constituído por uma mistura dos dois isómeros como se pode verificar por espectroscopia de infravermelho ou de NMR.

A forma cis pode ainda apresentar duas conformaçð̃es, energerticamente não equivalentes, a cis-transoide

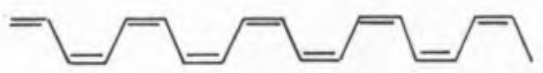

e a transcisoide

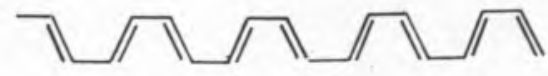

sendo a primeira a termodinamicamente mais estável e por isso aquela referida quando citamos a forma cis.
As duas conformaçōes possíveis do isomero trans são degeneradas sendo indiferente representar

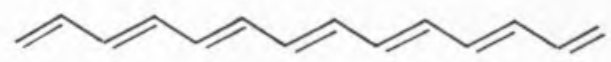

ou

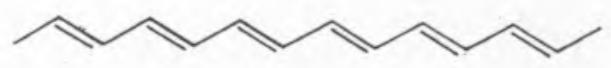

A configuração trans é termodinamicamente a mais estável o que explica a tendência do cis- $(\mathrm{CH})_{x}$ para se isomerizar passando portanto a trans- $(\mathrm{CH})_{x}$.

\section{2 - Estrutura e propriedades eléctricas}

Tendo presente o carácter conjugado das ligações na molécula do poliacetileno é de prever a possibilidade de deslocalização dos electrões $\pi$ ao longo da cadeia

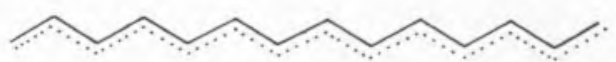

Esta deslocalização é uma condição necessária para haver condutividade eléctrica e por isso constituiria uma explicação para o poliacetileno ser um condutor unidimensional. Até 1977 nunca tinha sido possível testar esta propriedade pois a síntese conhecida levava à obtenção de um pó. Daí a importância do "acidente" a que nos referimos.

$\mathrm{Na}$ realidade o poliacetileno não apresenta uma condutividade metálica $\left(\approx 10^{-9}(\mathrm{ohm} \mathrm{cm})^{-1}\right.$ para o cis e $\approx 10^{-5}$ (ohm $\mathrm{cm})^{-1}$ para o trans) mas sim valores mais proximos dos semicondutores como o silício. Tal facto foi explicado por Peierls que demonstrou que uma cadeia unidimensional infinita com ligaçð̋es de igual comprimento é termodinamicamente instável. Uma deformação da rede provocando um abaixamento da energia cinética dos electrōes, torna-os mais localizados e conduz a ligações duplas e simples de diferente comprimento. A distorção da cadeia explica o aparecimento de um Gap entre as bandas $\pi$ do poliacetileno característico dos semicondutores. A largura do Gap no cis- $(\mathrm{CH})$, situa-se entre 1,9 e $2,2 \mathrm{eV}$ enquanto que no trans-(CH) é ligeiramente inferior, 1,4 a $1,6 \mathrm{eV}$.

As medidas de condutividade que têm sido efectuadas não permitem classificar as amostras como semicondu-

Centro de Química Física Molécular da Universidade Técnica de Lisboa. Complexo I do Instituto Nacional de Investigação Científica Instituto Superior Técnico - Av. Rovisco Pais 1069 LISBOA. 
tores intrínsecos pois a energia de activação do processo, à volta de $0,4 \mathrm{eV}$, é bem menor do que a largura da banda interdita. Este facto tem sido atribuído à existência de defeitos da cadeia bem como à presença de impurezas.

\section{3 - Dopagem do poliacetileno}

Dadas as suas características semicondutoras foram realizados ensaios de dopagem do poliacetileno. Os resultados foram notáveis pois, em certas condiçōes obervou-se um aumento de condutividade de um factor $10^{12}$ levando-o para valores que excedem os dos semicondutores dopados usuais, atingindo níveis da condutividade metálica. Por outro lado, a variação da condutividade em função da temperatura exibe um comportamento metálico. A figura 1 resume alguns valores de condutividade do poliacetileno dopado em comparação com o de outros materiais.

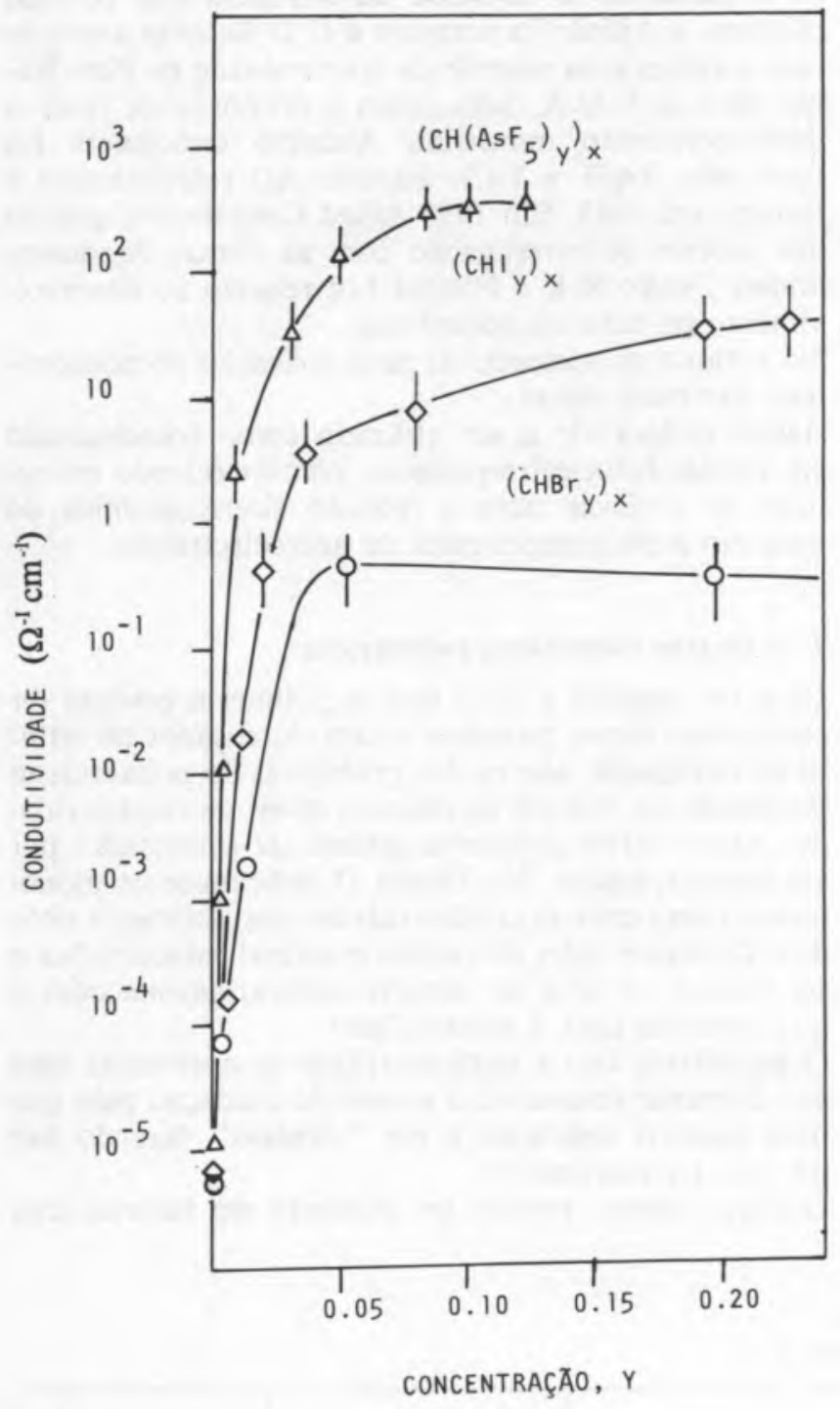

Figura 1

Variação da condutividade com a concentração de dopante

A dopagem do poliacetileno consiste numa oxidação ou redução dos carbonos da cadeia provocada pela introdução de impurezas apropriadas. Estas podem ser substâncias aceitadoras de electrőes (halogéneos, $\mathrm{AsF}_{5}$ etc.) ou doadoras de electrőes (metais alcalinos) originando deste modo poliacetileno do tipo p e $\mathrm{n}$ respectivamente.
Em princípio são possíveis três tipos de reacçð̃es da cadeia polimérica com moléculas:

1) Formação de ligações convalentes acompanhada de destruição do sistema $\pi$ do polimero como por exemplo a reacção

$$
\longrightarrow+\mathrm{Cl}_{2} \longrightarrow
$$

que transforma o polímero semicondutor num isolante. 2) Oxidação do polímero, isto é, transferência de um electrão do sistema $\pi$ do polímero para a molécula

$$
+3 / 2 \mathrm{l}_{2} \rightleftarrows
$$

A transferência de carga não envolve um simples despovoamento das orbitais ligantes $\pi$ mas, mais do que isso, leva à formação de uma entidade carregada positiva o que confere o carácter p ao semicondutor.

3) Redução do polímero, isto é, transferência de um electrão de uma espécie doadora para o sistema $\pi$ do polímero

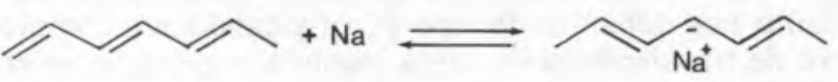

criando, para além do povoamento de orbiais $\mathrm{Na}^{+} \pi^{*}$ antiligantes, uma entidade carregada negativamente $\mathrm{e}$ conferindo portanto um carácter $\mathbf{n}$ ao semicondutor. O processo de dopagem pode ser químico ou electroquímico. $\mathrm{Na}$ dopagem química o polímero é exposto a uma atmosfera de vapor ou mergulhado numa solução do dopante. No processo electroquímico constitui-se uma célula em que os eléctrodos podem ser duas tiras de poliacetileno ligadas a uma bateria e mergulhadas num electrólito contendo o dopante. Por exemplo no caso de um electrólito contendo tetrabutilamina, o filme de poliacetileno que serve de ânodo é oxidado e fica dopado com o anião percloreto enquanto que o cátodo é reduzido e dopado com o catião tetrabutilamonio.

É interessante notar que a dopagem do poliacetileno é grandemente facilitada pelo facto da área exposta ao electrolito ser muito superior à sugerida por uma simples observação a olho nu. $\mathrm{Na}$ verdade, visto ao microscópio, o poliacetileno apresenta-se como um emaranhado de fibrilas entre as quais existe espaço vazio, o qual é acessível ao electrólito. O grande volume de espaços vazios traduz-se numa densidade da ordem de 0,4 contrariamente ao que acontece com outros filmes poliméricos.

\section{4 - Propriedades eléctricas de filmes dopados}

Como dissemos a condutividade eléctrica dos isómeros cis e trans do poliacetileno aumenta de muitas ordens de grandeza quando é dopado com espécies aceitadores ou doadores de electrōes. Este aumento é mais pronunciado no cis- $(\mathrm{CH})_{x}$ dopado no que no trans- $(\mathrm{CH})_{8}$ o que levou a supor que a dopagem da forma cis induz uma isomerização permitindo obter um trans de melhor qualidade do que o obtido por via térmica e posteriormente dopado.

A condutividade dos filmes de poliacetileno pode va- 
riar de valores típicos de um isolante $\left(\sigma \sim 10^{19}\right.$ (ohm $\mathrm{cm})^{-1}$ ), passar por um comportamento semicondutor até exibir valores típicos de metais $\left(\sigma \sim 10^{3}(\mathrm{ohm} \mathrm{cm})^{-1}\right)$. $\mathrm{O}$ comportamento típico da condutividade em função da concentração do dopante está representado na fig. 2 para três dopantes diferentes. $\mathrm{O}$ andamento geral é semelhante independentemente do dopante ser aceitador ou doador. Verificaram-se no entanto diferenças nos valores de saturação bem como do valor crítico da concentração para o qual ocorre a inflexão da curva.

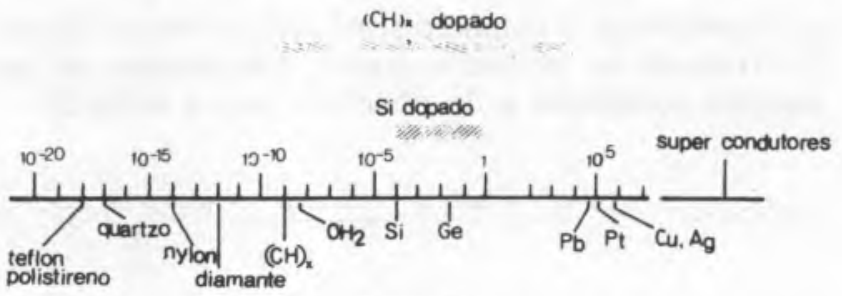

Figura 2

Escala de condutividades

\section{5 - Efeito do oxigénio nas amostras de (CH),}

$\mathrm{O}$ inconveniente mais importante do poliacetileno é a sua grande instabilidade quando exposto à atmosfera. Se a exposição não fôr muito longa, o oxigénio do ar pode actuar como dopante aceitador, incluindo-se portanto nos dopantes do tipo P, originando um complexo de transferência de carga segundo o processo reversível

$$
(\mathrm{CH})_{\mathrm{x}}+\mathrm{O}_{2}=(\mathrm{CH})_{\mathrm{x}}, \mathrm{O}_{2}
$$

No entanto uma exposição prolongada torna a reacção irreversível e conduz à degradação completa do polimero.

Esta elevada reactividade ao oxigénio obriga a trabalhar em condiçðes de atmosfera inerte o que efectivamente dificulta o manuseamento do poliacetileno e portanto a sua aplicação. Daí as várias tentativas que têm sido feitas para obstar este inconveniente, nomeadamente, as que procuram usar poliacetileno em materiais compositivos.

Recentemente Mac Diarmid afirmou que o poliacetileno pode ser dopado e estabilizado fazendo borbulhar oxigénio em meio aquoso desde que a dopagem seja feita nas condiçð̌es apropriadas.

\section{6- Aplicą̧ões}

$\mathrm{O}$ interesse da indústria não se fez esperar. Tinham-lhe acenado com um material condutor extremamente leve que pode ser dopado com electróes ou com lacunas.
Era o material há tanto tempo esperado para revolucionar a tecnologia das baterias e acumuladores.

$\mathrm{Na}$ verdade se pode ser dopado por via electroquímica o poliacetileno também deverá poder ser desdopado pela mesma via. Durante o processo de dopagem formam-se dois eléctrodos de poliacetileno com estados de oxidação iguais mas de sentido oposto. Se estes dois eléctrodos forem ligados entre si haverá um fluxo de electrőes do menos oxidado para o mais oxidado até que o estado de oxidação seja o mesmo, ou seja, até que o poliacetileno volte ao estado inicial, não dopado. Vários tipos de baterias foram testados na Universidade de Pensilvânia (Tabela I). Os valores de corrente são bastante elevados atendendo à quantidade da amostra ou seja a densidade de energia (watt-por $\mathrm{Kg}$ ) poderá vir a exceder a das baterias convencionais. Sendo tão leves seriam assim as baterias ideais para os veículos eléctricos.

A testemunhar o interesse da indústria nas baterias plásticas a Allied Corporation e C D Bateries anunciaram a compra da patente da Universidade de Pensilvânia para os E.U.A. bem como o propósito de fazer o desenvolvimento industrial. Anúncio semelhante foi feito pela BASF e Varle Batterie AG relativamente à Europa em 1983. Em 1984 Allied Corporation assinou um acordo de investigação com as firmas Japonesas Showe Deuko K-K e Hitachi Ltd relativo ao desenvolvimento de baterias poliméricas.

No entanto as perspectivas para aplicação do poliacetileno são mais vastas.

Assim poderá vir a ser utilizado como fotoelectrodo em células fotoelectroquímicas, como eléctrodo em células de potência para a redução electrocatalítica do oxigénio e em componentes de microelectrónica.

\section{7 - Outros condutores poliméricos}

Uma vez lançada a ideia que os polímeros podiam ser condutores vários produtos foram sintetisados no intuito de ultrapassar alguns dos problemas do poliacetileno mantendo no entanto os mesmos níveis de condutividade. Assim vários polímeros podem ser sintetisados por via electroquímica. Na Tabela II indicam-se os monómeros bem como as condutividades dos polimeros obtidos. Qualquer deles têm como principal característica o ser estável ao ar e ser amorfo contrariamente com o que acontece com o poliacetileno.

O polipirrole tem a particularidade de apresentar uma cor diferente consoante o estado de oxidação pelo que uma possível aplicação é em "displays" fazendo uso do seu electrocromismo.

Qualquer destes poderá ser utilizado em baterias mas

Tabela 1

Baterias orgânicas

\begin{tabular}{|c|c|c|c|c|c|}
\hline & Anodo & Catodo & $\begin{array}{c}\text { Valores } \\
\text { Experimentais }\end{array}$ & Voltagem & Corrente \\
\hline $\begin{array}{r}\text { Tipo I } \\
\mathrm{a}<\mathrm{b}\end{array}$ & $\left(\mathrm{CH}^{+2}\right)_{x}$ & $\left(\mathrm{CH}^{+b}\right)_{x}$ & $\begin{array}{l}a=0,02 \\
b=0,05\end{array}$ & 0,5 & $0,3 \mathrm{~mA}$ \\
\hline Tipo II & $\left(\mathrm{CH}^{-5}\right)_{x}$ & $\left(\mathrm{CH}^{+d}\right)_{x}$ & $\begin{array}{l}c=0,024 \\
d=0,024\end{array}$ & 2,5 & $11,1 \mathrm{~mA}$ \\
\hline$\underset{\mathrm{e}>\mathrm{f}}{\text { Tipo III }}$ & $\left(\mathrm{CH}^{-5}\right)_{x}$ & $\left(\mathrm{CH}^{-1}\right)_{x}$ & $\begin{array}{l}e=0,07 \\
f=0,02\end{array}$ & 0,66 & $1,9 \mathrm{~mA}$ \\
\hline
\end{tabular}


Tabela II

Condutividade dos polímeros obtidos por via electroquímica dos monómeros indicados

\begin{tabular}{|c|c|}
\hline Monómeros & $\begin{array}{c}\text { Condutividade } \\
\sigma\left(\Omega^{-1} \mathrm{~cm}^{-1}\right)\end{array}$ \\
\hline & $30-100$ \\
\hline &
\end{tabular}

nenhum, ou qualquer outro polímero condutor, tem uma área específica comparável à do poliacetileno.

Recentemente foi focado o interesse de polímeros em forma de "espetada"

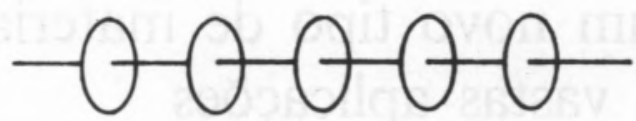

em que os elementos "espetados" são compostos com ligaçð̃es conjugadas como por exemplo ftalocianinas mantidas através de um "espeto" à distância correcta para permitir a transferência de carga.

Que futuro?

Além de todas as aplicaçðes que se antevêm já num futuro mais ou menos próximo, a existência de polímeros orgânicos condutores permite-nos começar a acreditar naquilo que hoje ainda é quase ficção científica -0 computador molecular.

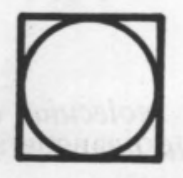

\section{DINAMISMO - QUALIDADE - SERVIÇO}

\section{ESCOLHA - EFICIÊNCIA}

PEÇA-NOS A LISTA DAS NOSSAS REPRESENTADAS

ALGUMA LHE INTERESSARÁ!

Estamos à distância do seu telefone...

QUINTA DA PIEDADE, LOTE $12-1 .^{\circ}$ 